DOI 10.37882/2223-2974.2020.10.44

\title{
ПОНЯТИЙНЫЕ ПРИЗНАКИ ОБРАЗОВАТЕЛЬНОЙ УСЛУГИ КАК ОБЪЕКТА ГРАЖДАНСКИХ ПРАВ
}

\section{CONCEPTUAL FEATURES \\ OF EDUCATIONAL SERVICES AS AN OBJECT OF CIVIL RIGHTS}

T. Shtepa

Summary: The purpose of the article is to determin the feature complex of educational service as the object of civil rights. Meanwhile, the contractual obligation for service delivery is the subject of research. The object of these binding relationship is the customer's demand of the educational service in relation to contractor's actions and their further positive perception of the Contractor's commitment. It is clear that an educational service belongs to a group of services that do not imply any result. Therefore, the criterion for performing an educational service is an indicator of the effectiveness of the service Contractor's commitment. It is established that due to the fact that educational services are services for which the actions of the service provider cannot be completed by achieving a certain result, there is a need for a legal assessment of their behavior in the process of fulfilling obligations. However, this procedure is difficult to implement in practice due to the lack of generally accepted legal parameters of educational services both in the current legislation and in the legal doctrine. Based on the results of the analysis, a number of distinctive features of educational services are proposed. The author's definition of an educational service is derived, taking into account its main features.

Keywords: contract for the provision of educational services; educational service; distinctive features of educational services; object of civil rights; service provider; service customer.
Штепа Татьяна Владимировна

Аспирант, Российский университет транспорта (МИИТ) t.v.shtepa@mail.ru

Аннотация: Целью статьи является определение комплекса признаков образовательной услуги как объекта гражданских прав. При этом предметом исследования выступает договорное обязательство по предоставлению услуги, в котором объектом таких обязательственных правоотношений является требование заказчика образовательной услуги относительно совершения исполнителем соответствующих предметных действий и дальнейшее его положительное восприятие относительно выполнения им своих обязанностей. Определено, что образовательная услуга относится к группе услуг, которые не предусматривают возникновения какого-либо результата (эффекта). Это обуславливает использование в качестве критерия выполнения образовательной услуги показатель результативности действий исполнителя услуги. Установлено, что в связи с тем, что образовательные услуги относятся к услугам, по которым действия исполнителя услуг не могут завершаться достижением определенного результата, возникает необходимость в юридической оценке их поведения в процессе выполнения обязательств. Однако данная процедура сложно реализуема на практике из-за отсутствия как в действующем законодательстве, так и в правовой доктрине общепринятых юридических параметров образовательных услуг. По результатам анализа предложен ряд отличительных признаков образовательных услуг. Выведено авторское определение образовательной услуги, учитывающее ее основные признаки.

Ключевые слова: договор оказания образовательных услуг; образовательная услуга; отличительные признаки образовательной услуги; объект гражданских прав; исполнитель услуги; заказчик услуги. бразовательная услуга является результатом духовно-интеллектуального производства, одним из продуктов экономики знаний, который персонифицируется в значительном числе потребителей. Невзирая на значительное количество публикаций, до сих пор не выведено общепринятого представления о сущности образовательной услуги, не завершено определение ее природы и не определены в полной мере отличительные характеристики. Необходимость определения понятийных признаков образовательной услуги как объекта гражданских прав вызвано практическими потребностями установления критериев оценки надлежащего поведения исполнителей данного вида услуг.

Анализ содержания имеющихся работ указывает на то, что многие авторы ставили перед собой цель определения свойств образовательной услуги именно как разновидности объектов гражданских прав. Это объясняется специфическим направлением таких исследований, которые проводились такими авторами, как Зарубина М.Г. [7], Дроздова А.В. [2], Попова Д.Г. [15], Рожков А.И. [18], Сахарова Е.А. [19], Степанов Д.И. [20]. Значительное внимание различным аспектам оказания образовательных услуг уделял Кокорин И.С. [11; 12]. Тем не менее, данный вопрос остается открытым, особенно в части разграничения публично-правового и частноправового характера образовательных услуг, что непосредственно исследовался уже значительно меньшим количеством авторов.

Относительно гражданско-правового регулирования предоставления услуг в сфере образования Сырых B.М. указывает, что в образовательных отношениях отсутствуют основополагающие черты гражданского правоотношения - свобода воли и равенство сторон. Единственное условие, которое привлекает авторов 
рассмотрения образовательных отношений как разновидности услуги, по его мнению, и что действительно присуще им, - это платный имущественный характер образовательных отношений, которые возникли в силу оплаты стоимости образования самим учеником или его родителями [21, с. 73-74].

В Российской Федерации согласно п. 3 ст. 2 ГК РФ к имущественным отношениям, основанным на административном или властном подчинении одной стороны другой, гражданское право не применяется, если иное не предусмотрено законодательством. Это же положение, по мнению российского ученого, в полной мере распространяется и на образовательные отношения $[21$, c. 74].

Некоторые авторы не только выделяют хозяйственные отношения в сфере образования, но и отделяют их по форме собственности. Так, М.О. Тимошенко, определив особенности хозяйственных отношений частных вузов, отмечает, что они представляют собой самостоятельную разновидность хозяйственных правоотношений, которые формируются при участии частных вузов, и содержанием которых является предоставление образовательных услуг в сфере высшего образования с выдачей соответствующего документа об образовании и/или обеспечении предоставления указанных услуг [22, с. 217].

ГК РФ 1994 г. оформил законодательно услугу как объект гражданского права, но не сформулировал ее понятие [1, ст. 128 в ред. Федерального закона от 18.03.2019 № 34-Ф3]. Ее понятие отсутствует и в законах в сфере услуг, принятых до и после принятия Гражданского кодекса. Нормативные акты в различных видах деятельности в основном перечисляют присущие данному виду деятельности услуги, либо характеризуют их в широком понимании, не раскрывая специфической природы услуги как таковой.

Ученые в сфере гражданско-правовых отношений сегодня не пришли к единому мнению в отношении сущности услуги, ее соотношения с товаром. В частности, А.Ю. Кабалкин считал невозможным применять в обороте конструкцию «договор услуг» [8, с. 44-45, 48]. В дальнейшем он указывал, что они «не могут быть самостоятельным типом гражданско-правового обязательства» [9, с. 38]. Ученый не признавал услуги самостоятельным институтом: «Невозможно согласиться в настоящее время с признанием этих обязательств своеобразным правовым институтом, особенно в условиях, когда в гражданском законодательстве отсутствовали нормы, которые регулировали отношение по предоставлению услуг как таковых».

Существуют и полностью диаметральные точки зре- ния. Так М.В. Кротов считал, что обязательство по предоставлению услуг является самостоятельным институтом обязательственного права [10, с. 89].

Исследователи гражданско-правовой сущности услуг подразделяют их на услуги, которые завершаются определенным невещественным результатам (эффектом), и услуги, в результате употребления которых не предусмотрено возникновение какого-либо результата (эффекта). В первом случае критерием выполнения услуги служит результативность действий исполнителя услуги, а во втором - непосредственно поведение исполнителя. В рамках данной градации образовательные услуги следует отнести к первой группе, т.е. их исполнение не дает непосредственного эффекта.

С.А. Загородний, к примеру, к специальным критериям оценки надлежащего поведения исполнителя в процессе предоставления образовательных услуг относит:

- соблюдение исполнителем технологической дисциплины;

- общая политика деятельности исполнителя относительно соблюдения качества предоставление услуг;

- уровень завершенности осуществленной исполнителем деятельности;

- качество обслуживания [4].

В связи с тем, что образовательные услуги относятся к услугам, по которым действия исполнителя услуг не могут завершаться достижением определенного результата, возникает необходимость в юридической оценке их поведения в процессе выполнения обязательств. В этом аспекте проблемным моментом является отсутствие, как в действующем законодательстве, так и в правовой доктрине общепринятых юридических параметров образовательных услуг. К примеру, в общих положениях об услугах в ГК РФ можно встретить только указание на то, что исполнитель услуги обязывается по заданию заказчика оказать услугу, которая потребляется в процессе совершения определенного действия или осуществления определенной деятельности, и то, что исполнитель должен оказать услугу лично (ст. 780 ГК РФ). Очевидно, вышеприведенных предписаний недостаточно, чтобы оценить содержательное поведение исполнителя образовательной услуги.

Аналогичный вывод можно сделать, исходя из анализа специальных нормативных требований, то есть положений образовательного законодательства. В ст. 2 Закона об образовании даны 34 основных понятия, непосредственно в тексте закона приведено еще порядка 70 различных определений [5]. Однако Закон об образовании не содержит непосредственной трактовки данного термина, в то же время он встречается в тексте в 
различных контекстах. Данная ситуация позволяет говорить о нерешенности отмеченной проблемы на законодательном уровне.

Однако наличие определения термина в специальном нормативном поле еще не дает оснований говорить о присутствии содержательной характеристики. Так, к примеру, Закон Украины «Об образовании» трактует, что образовательная услуга - это «комплекс определенных законодательством, образовательной программой и/или договором действий субъекта образовательной деятельности, что имеют определенную стоимость и направлены на достижение получателем образования ожидаемых результатов обучения» [6]. Такая формулировка понятия образовательной услуги также не очерчивает ее содержательной характеристики.

В подзаконных нормативных актах анализируемый термин также широко используется, и в некоторых приведено его определение. К примеру, в приказах Минобрнауки России № 499 [16] и № 8 [17] под образовательными услугами подразумевается любая образовательная деятельность.

При этом стоит также отметить, что образовательная сфера в Российской Федерации постоянно подвергается реформациям, что приводит к непостоянству законодательной терминологии. Это касается, в том числе, и терминологического обозначения образовательной услуги.

Образовательная услуга получает внешнее проявление при активном поведении исполнителя. Предметное поведение образовательной организации или другого лица, оказывающего услуги по обучению/воспитанию, и есть собственно образовательная услуга. Следовательно, понимание образовательной услуги тесно связано со способностью исполнителей совершать надлежащие акты поведения определенной содержательной наполненности. Законодатель, по всей видимости, также придерживается данной позиции, закрепив в общих нормах об услугах положение о том, что исполнитель должен оказать услугу лично (ст. 780 ГК РФ).

Следовательно, профессиональная квалификация педагогического состава образовательной организации или физического лица, которые оказывают образовательную услугу, определяет качество предоставления данных услуг. Выбирая образовательную организацию или исполнителя образовательной услуги, заказчик в первую очередь ориентируется на их профессиональную репутацию и уровень квалификации исполнителей, что позволит ему получить образовательную услугу с надлежащими потребительскими свойствами и уровнем качества.

Цель поведения исполнителя заключается в форми- ровании у заказчика (субъект обучения) новых профессиональных, социальных и жизненных качеств, которые будут использоваться им в повседневной жизни или профессиональной деятельности. В то же время исполнитель не может в одностороннем порядке нести гражданско-правовую ответственность за результаты обучения, поскольку они в определенной степени зависят и от деятельности (активности) и интеллектуальных способностей заказчика, а также от ряда других факторов.

По результатам анализа нами предлагается выделять такие отличительные признаки образовательных услуг:

- результат духовно-интеллектуального производства, один из продуктов экономики знаний, который персонифицируется в значительном числе потребителей;

- значительная степень индивидуализации и эксклюзивности [15];

- наличие элемента имущественных отношений;

- наличие государственного и публичного контроля за процессом их оказания, содержанием и качеством;

- содержание образования как предмет услуги не может быть оценено в денежной форме, хотя в дальнейшем может принести материальные блага, в то время как стоимость образовательных услуг оценивается сторонами договора;

- одновременность предоставления и потребления услуги [23];

- ограниченное разовое потребление, усложненность замены поставщика услуги из-за значительных расходов, наличие одновременно платных и бесплатных услуг, качество услуги может быть оценено потребителем только в процессе ее потребления (на наш взгляд, не в процессе, а после) [3];

- одновременное предоставление услуги значительному количеству лиц [14];

- неограниченный срок использования результата оказанной услуги, значимость для общества, системность и профессиональная направленность [13];

- неопределенность содержания: заказчик не знает в полной мере полного содержания услуги и, с другой стороны, непосредственный исполнитель (преподаватель) до начала оказания услуги не знает ее полного содержания [18];

- всегда имеет свою стоимость, цену и возмездный характер оказания.

Под образовательной услугой предлагается понимать организованную систематическую коммуникативную деятельность в учебных заведениях по воспитанию и обучению обучаемых в соответствии с государственным образовательным стандартом с выдачей подтверждающего образовательного документа законодательно установленной формы. 
1. Гражданский кодекс Российской Федерации от 30.11.1994 N 51-Ф3.

\section{ЛИТЕРАТУРА}

2. Дроздова А.В. Сибирский юридический вестник // Понятие и содержание услуги как объекта гражданских прав. - 2003. - № 1. - С. 39-44.

3. Жиляев И.Б. Формирование рынка образовательных услуг высшей школы Украины // Научно-практическая конференция «Проблемы модернизации и систематизации законодательства 06 образовании Украины». - Киев 27-28 мая 2010 г. - К.: Нора-печать 2010. - С. 37-40.

4. Загородний С.А. Договор о профессиональной подготовке в высшем учебном заведении: дис. ... канд. юрид. наук: 12.00.03. - Харьков, 2007. - 188 с.

5. Федеральный закон от 29 декабря 2012 г. № 273-Ф3 «06 образовании в Российской Федерации».

6. Закон Украины от 5.09.2017 г. № 2145 «06 образовании».

7. Зарубина М.Г. Гражданско-правовое регулирование оказания платных образовательных услуг // Юридическая наука. - 2017. - № 4. - С. $16-21$.

8. Кабалкин А.Ю. Сфера обслуживания: гражданско-правовое регулирование. - М.: Наука, 1972. - 200 с.

9. Кабалкин А.Ю. Услуги в гражданском праве Российской Федерации // Сборник научных трудов, посвященных памяти В.А. Рясенцева. - М.: Юристь, 1995. - C. $34-43$.

10. Кротов М.В. Обязательства по оказанию услуг в советском гражданском праве. - Л., 1990. - 189 с.

11. Кокорин И.С. Предмет договора возмездного оказания образовательных услуг: проблемы понимания // Ленинградский юридический журнал. - 2016. № 2. - C. 64-71.

12. Кокорин И.С., Очередько В.О. Гражданско-правовая характеристика договора об оказании возмездных образовательных услуг // Ленинградский юридический журнал. - 2015. - № 4 (42). - С. 12-14.

13. Кудряшов И.В. Договор на оказание платных образовательных услуг как основание инвестиций в образование // Право и образование. - 2008. - № 2. C. 25-33.

14. Плискина А.В. Вопросы регулирования в сфере образовательных услуг // Современные исследования социальных проблем: Сборник статей 0бщероссийской научно-практической конференции. Вып. 3. Социально-экономические проблемы развития общества. - Красноярск: Научно-инновационный центр, 2009. - С. 150-155

15. Попова Д.Г. Услуга как объект гражданских прав и ее соотношение с категорией «социальная услуга» // Вестник Кемеровского государственного университета. - 2012. - № 4 (52). - Т. 1. - С. 351-358.

16. Приказ Минобрнауки России от 01.07.2013 г. № 499. «06 утверждении порядка организации и осуществления образовательной деятельности по дополнительным профессиональным программам».

17. Приказ Минобрнауки России от 13.01.2014 г. № 8 «06 утверждении примерной формы договора об образовании по образовательным программам дошкольного образования»

18. Рожков А.И. Образовательные услуги как объект гражданских прав: проблемы правового определения // Право и образование. - 2007. - № 7. - С. 11-18.

19. Сахарова Е.А. Образовательная услуга как объект гражданских прав: понятие, специфика, классификация // Теория и практика современной науки. 2016. - № 11 (17). - С. 703-711.

20. Степанов Д.И. Услуги как объект гражданских прав: Дис. ... канд. юрид. наук: 12.00.03. - М., 2004. - 315 с.

21. Сырых В.М. Образовательные услуги и образовательные правоотношения: дискуссионные взгляды и действительное содержание // Журнал российского права. - 2010. - № 4. - С. 69-78.

22. Тимошенко М.0. Особенности хозяйственных правоотношений частных высших учебных заведений Украины: правовой аспект // Вестник Луганского государственного университета внутренних дел имени Э.0. Дидоренко. - 2010. - № 3. - С. 213-220.

23. Шкарлупина Г.Д. Образовательные услуги и нормы права // Право и образование. - 2009. - № 1. - С. 71-81.

(с) Штепа Татьяна Владимировна (t.v.shtepa@mail.ru).

Журнал «Современная наука: актуальные проблемы теории и практики» 